\title{
ZONEAMENTO MORFOLITOLÓGICO DA BACIA HIDROGRÁFICA DO RIO IBICUII E SUA RELAÇÃO COM PROCESSOS SUPERFICIAIS E O USO DO SOLO
}

\section{MORPHOLITHOLOGIC ZONING OF RIVER IBICUÍ BASIN AND ITS RELATIONSHIP WITH SURFACE PROCESSES AND LAND USE}

\author{
Luis Eduardo de Souza Robaina \\ Departamento de Geociências, Universidade Federal de Santa Maria \\ Av. Roraima, 1000, Camobi, Santa Maria, Rio Grande do Sul, CEP: 97105-900, Brasil \\ Email: lesrobaina@yahoo.com.br \\ Romário Trentin \\ Departamento de Geociências, Universidade Federal de Santa Maria \\ Av. Roraima, 1000, Camobi, Santa Maria, Rio Grande do Sul, CEP: 97105-900, Brasil \\ Email: romario.trentin@gmail.com
}

François Laurent

Université du Maine Avenue Olivier Messiaen, 72085 - Le Mans cedex 9, França Email: francois.laurent@univ-lemans.fr

Anderson Augusto Volpato Sccoti

Departamento de Geociências, Universidade Federal de Santa Maria Av. Roraima, 1000, Camobi, Santa Maria, Rio Grande do Sul, CEP: 97105-900, Brasil

Email: asccoti@yahoo.com.br

\section{Informações sobre o Artigo}

Data de Recebimento:

$16 / 11 / 2014$

Data de Aprovação:

20/02/2015

\section{Palavras-chave:}

Zoneamento; Morfolitológico; Rio Ibicuí.

\section{Keywords:}

Zoning; Morpholithologic; River Ibicuí.

\section{Resumo:}

Este trabalho apresenta um zoneamento baseado nos componentes do substrato representados pelas litologias e as formas de relevo da Bacia hidrográfica do Rio Ibicuí. A Bacia Hidrográfica do Rio Ibicuí está localizada entre as coordenadas de latitude sul $29^{\circ} 01^{\prime}$ e $31^{\circ} 20^{\prime}$ e entre as longitudes oeste $56^{\circ} 47^{\prime}$ e $53^{\circ} 29^{\prime}$, englobando a área total ou parcial de 30 municípios. A identificação das litologias na Bacia Hidrográfica do Rio Ibicuí se deu através de informações disponibilizadas pelo mapeamento geológico do Rio Grande do Sul (WILDNER, 2006) na escala 1:750.000 e perfis de trabalhos de campo. Para a definição das unidades de relevo foram usadas imagens de Radar SRTM, construindo um modelo digital de elevação e a partir deste foram gerados produtos secundários das vertentes como, declividade, amplitudes, perfil e plano de curvatura da encosta. Os planos de informações gerados (altimetria, declividade, plano e perfil de curvatura), foram reclassificados em classes, utilizando limites específicos para a caracterização de cada uma das variáveis em questão. O SIG (Sistemas de Informações Geográficas) 
utilizado na interpolação de informações foi o ArcGis 10, disponibilizado pela ESRI. As caraterísticas do relevo e do substrato definiram 11 unidades morfolitológicas, que em alguns casos foram divididas em subunidades, definidas por: unidade do Planalto com a subunidade Tupanciretã; unidade Rebordo; unidade Morros testemunhos; unidade Serra do Caverá; unidade Maciço cristalino com as subunidades granito-gnaisses, Platô Taquarembó e Rio Bonito; unidade colinas de arenitos com as subunidades Cacequi, Rosário, Fossilífero e Guará; unidade colinas do Caverá; unidade Ibirapuitã; unidade Ibirocai; unidade de áreas planas em lamitos; unidade de áreas planas em depósitos recentes. O trabalho permitiu verificar a influência das unidades morfolitológicas com os processos superficiais atuantes, com as características dos solos e com os usos.

\begin{abstract}
:
This paper presents a zoning based on components of the lithologies represented by the substrate and the relief of catchment area of Ibicuí River. The Ibicui River watershed is located between the coordinates of south latitude $29^{\circ} 01^{\prime}$ and $31^{\circ} 20^{\prime}$ ' and between west longitude $56^{\circ} 47$ 'and 53 $29^{\circ}$ ', involving the partial or total area of 30 municipalities. The identification of lithologies in Ibicui River watershed was through information provided by the geological mapping of Rio Grande do Sul (WILDNER, 2006, 1: 750,000) and fieldwork profiles. For the definition of the relief units were used radar images of SRTM, building a digital elevation model, and from this side of the product strands as, slope, amplitude, profile and plan curvature of the slope were generated. The plans of the information (altitude, slope, plan and profile curvature), were reclassified into classes using specific characterization of each of the variables in question limits. The GIS (Geographic Information Systems) used in the interpolation of information was the ArcGIS 10, available from ESRI. The features of relief and of the substrate 11 defined morpholithologics units, which in some cases were divided into subunits, defined by: Plateau unit with one Tupanciretã subunit; edge of the plateau unit; buttes testimonies unit; Serra de Caverá unit; Massive crystalline unit with subunits granitegneisses, Taquarembó Plateau and Rio Bonito; hills of sandstones unit with Cacequi, Rosario, Fossilífero and Guára subunits; hills of Caverá unit; Ibirapuitã unit; Ibirocai unit; flat areas unit on mudstone; flat areas unit on recent deposits. The work demonstrated the influence of morpholithologics units with the surface processes, soil characteristics and uses.
\end{abstract}

\section{Introdução}

A região oeste do Rio Grande do Sul apresenta como características ambientais marcante o desenvolvimento de processos erosivos avançados como o desenvolvimento de ravinas, voçorocas e a formação de areais. Os registros destas características remontam desde meados do séc. XIX, quando o médico naturalista Robert Avé-Lallemant fez o mais antigo relato que se conhece da presença de areais no oeste gaúcho, no ano de 1858. Na década de 1970, esta região registrou uma acentuada aceleração dos processos erosivos fruto da intensificação da atividade agrícola mecanizada, o que levou a despertar nos pesquisadores maior atenção.

A compreensão destas caraterísticas de dinâmica superficial do oeste do Rio Grande do Sul ocorre por meio de estudos dos principais atributos do meio físico. Dentre muitos trabalhos relevantes que abordam esta problemática, destacam-se o de Souto (1985), Suertegaray (1995 e 2001), Verdum (1997), os mapeamentos geológico-geomorfológico de Paula (2006), Trentin et al. (2012; 2013), Trentin \& Robaina (2012), Robaina et al.(2013), Sccoti et al. (2013) e Menezes et al. (2012; 2013) realizados em bacias hidrográficas e em municípios da Bacia Hidrográfica do Rio Ibicuí (BHRI).

Nesses estudos a cartografia é utilizada como meio de representação gráfica e espacial das formas do relevo e suas relações com a estrutura e os processos. O sistema natural é composto de vários elementos que desencadeiam os processos que agem na modificação do relevo. Estes elementos desenvolvem a esculturação e modelagem do relevo, que constantemente é modificado, marcando um processo de retroalimentação, característico de um sistema aberto onde há entrada e saída de energia.

As formas de relevo e as litologias constituem o substrato físico sobre o qual se desenvolvem as atividades humanas e dessa forma, trabalhos de zoneamentos que determinam unidades homogêneas são fundamen- 
tais para entendimento dos processos geomorfológicos e como as ações humanas podem interferir no meio.

Este trabalho apresenta um zoneamento baseado nos componentes do substrato representados pelas litologias e as formas de relevo da Bacia hidrográfica do Rio Ibicuí (BHRI). Segue propostas apresentadas por Pallí i Buxó (1981) na Espanha, Trentin \& Robaina (2006) e Alves \& Robaina (2010) que trabalharam com mapeamentos morfolitológicos no oeste do Rio Grande do Sul, Brasil. Além desses, se fundamenta em trabalhos como: Enríquez (2012) que utiliza uma cartografia morfolitológica para estudo de fluxo de lama; Barreiros (2013) que usa um mapeamento morfolitologico para estudar os solos, da bacia do córrego Gurupá, Floraí, PR; e o trabalho de Guadagnin e Trentin (2014), que estabelece relação da vegetação e relevo na bacia hidrográfica do Arroio Caverá, oeste do RS.

A área de estudo corresponde a Bacia Hidrográfica do Rio Ibicuí, que é responsável por drenar as porções central e oeste do Rio Grande do Sul, sendo assim, uma das principais bacias de drenagem do Estado. A BHRI está localizada (Figura 1) entre as coordenadas de latitude sul $29^{\circ} 01^{\prime}$ e $31^{\circ} 20^{\prime}$ e entre as longitudes oeste $56^{\circ} 47^{\prime}$ e 53⒉', englobando a área total ou parcial de 30 municípios.

Aárea da bacia é de $46.602,58 \mathrm{~km}^{2}$, o perímetro de 1268,76 km e o canal principal apresenta uma extensão de $1.302 \mathrm{~km}$, desde a nascente do Rio Santa Maria até a foz quando o Rio Ibicuí deságua no rio Uruguai.

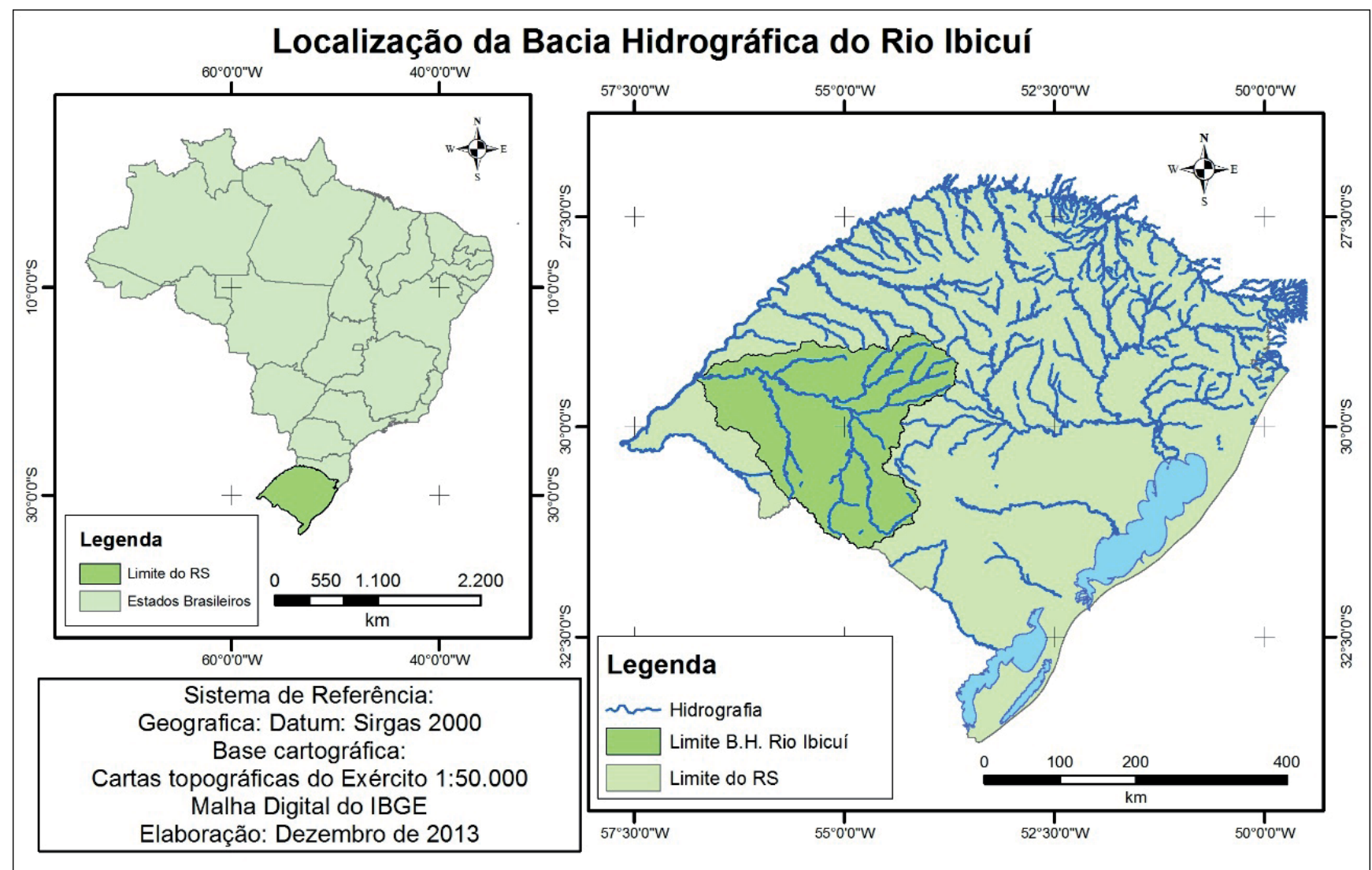

Figura 1 - Mapa de localização da área de estudo

\section{Metodologia}

A identificação das litologias na BHRI se deu através de informações disponibilizadas pelo mapeamento geológico do Rio Grande do Sul (WILDNER, 2006) na escala 1:750.000 e perfis de trabalhos de campo, com observações e descrições das principais características observadas, como mineralogia, textura e estruturas.

Para a definição das unidades de relevo foi utilizado o Modelo Digital de Elevação gerado através da Shuttle Radar Topography Mission (STRM) e, a partir deste foram gerados produtos secundários das vertentes como, declividade, amplitudes, perfil e plano de curvatura da encosta. 
Os planos de informações gerados (altimetria, declividade, plano e perfil de curvatura), foram reclassificados em classes, utilizando limites específicos para a caracterização de cada uma das variáveis em questão. $\mathrm{Na}$ altimetria utilizou-se os limites que indicavam quebras naturais de relevo, relacionadas às áreas mais baixas da bacia hidrográfica associadas às áreas de planície, os limites de base e topo do rebordo do planalto que definem uma esculturação diferenciada na bacia hidrográfica.

As classes de declividade foram definidas de acordo com proposta do Instituto de Pesquisas Tecnológicas - IPT (1981) que trabalha com classificação de formas de relevo e utiliza os limites de 2, 5 e $15 \%$ de declividade na definição das formas. O limite de $2 \%$ associa-se as áreas planas relacionadas à deposição de sedimentos, quando próximo aos cursos de água, ou aos topos planos nas maiores altitudes. O limite de 5\% indica o início dos processos erosivos e, o limite de 15\% está associado às áreas susceptíveis aos movimentos de massa e escorregamentos.

As amplitudes foram obtidas pela diferença de cotas, medidas diretamente na carta através de perfis. Estes perfis são traçados dos pontos de maior elevação da vertente, obtidos por meio da identificação dos pontos cotados ou curvas de nível, até a porção de interflúvio, onde o curso de água delimita a porção baixa da vertente e é obtido o valor de menor altitude. Os valores de amplitude são obtidos aleatoriamente sempre seguindo uma determinada homogeneidade de observações em cada uma das sub-bacias que compõem a BHRI.

Quanto ao perfil de curvatura são utilizadas as curvaturas côncavas e convexas, para isso utiliza-se o limite 0 (zero) para definição das duas classes, onde os valores negativos correspondem as curvaturas convexas e os valores positivos correspondem as curvaturas côncavas. Já o plano de curvatura das vertentes é analisado quanto às curvaturas convergentes, planar e divergentes. Neste caso os valores muito próximos de 0 (zero), são definidos como vertentes planares, já os valores negativos são definidos como vertentes convergente e os valores positivos como vertentes divergentes.

O cruzamento destes planos de informação define as unidades de relevo presentes na bacia hidrográfica, que posteriormente são cruzadas com as informações litológicas para a definição das unidades morfolitológicas.
Os trabalhos de campo foram realizados através de perfis, seguindo as rodovias e caminhos, nos pontos de parada, eram coletados pontos com o receptor GPS (Garmim 62Sx) que posteriormente foram usados na delimitação de informações necessárias.

O SIG (Sistemas de Informações Geográficas) utilizado na interpolação de informações foi o ArcGis 10, disponibilizado pela ESRI.

As unidades de relevo utilizadas são adaptadas da classificação desenvolvida pelo IPT 1981 (Instituto de Pesquisas Tecnológicas), definindo morros, morrotes, colinas e áreas planas.

\section{Resultados}

Geomorfologicamente a BHRI encontra-se inserida nas unidades geomorfológicas da Depressão Periférica do Rio Grande do Sul, do Planalto da Serra Geral e, ainda, uma pequena parte, a sudeste, do Escudo Sul-riograndense (ROBAINA et al. 2010).

Conforme a hierarquização da drenagem de Strahler (apud CHRISTOFOLETTI, 1980) o canal principal do rio Ibicuí, apresenta como resultante a $8^{\mathrm{a}}$ ordem, considerado o canal fluvial principal a partir do encontro com o Rio Santa Maria.

Os trabalhos de análise dos atributos do relevo como altitude, amplitude, declividade e forma das encostas permitiram definir 04 formas de relevo, que ocorrem na bacia, que são as áreas planas, as colinas e os morros e morrotes, figura 2.

As áreas planas, que são caracterizadas por declividades inferiores a $2 \%$ e estão dominantemente associadas aos vales dos grandes rios da região.

As colinas, são as formas predominantes, e caracterizam-se por amplitudes entre 20 e $60 \mathrm{~m}$ e por declividades variando de $2 \%$ a inferiores a $15 \%$. Foram divididas em colinas de altitude, quando localizadas nas áreas mais elevadas, dentro da bacia (altitudes variando de 300 m a 546 m), no Planalto da Serra Geral; colinas suaves quando as declividades estão entre $2 \%$ e $5 \%$; e as colinas propriamente ditas com declividades entre $5 \%$ e $15 \%$.

Os morros e morrotes são formas caracterizadas por declividades das encostas superiores a $15 \%$, sendo diferenciados por amplitudes superiores a $100 \mathrm{~m}$ nas formas de morros e inferiores nos morrotes. Ocorrem 
de forma isolada, marcando o recuo da escarpa do Planalto; formando um alinhamento estrutural denominado “Serra do Caverá”, na região centro-sul da bacia e; na transição da Depressão Periférica para o Planalto, constituindo vales encaixados com importantes depósitos superficiais.

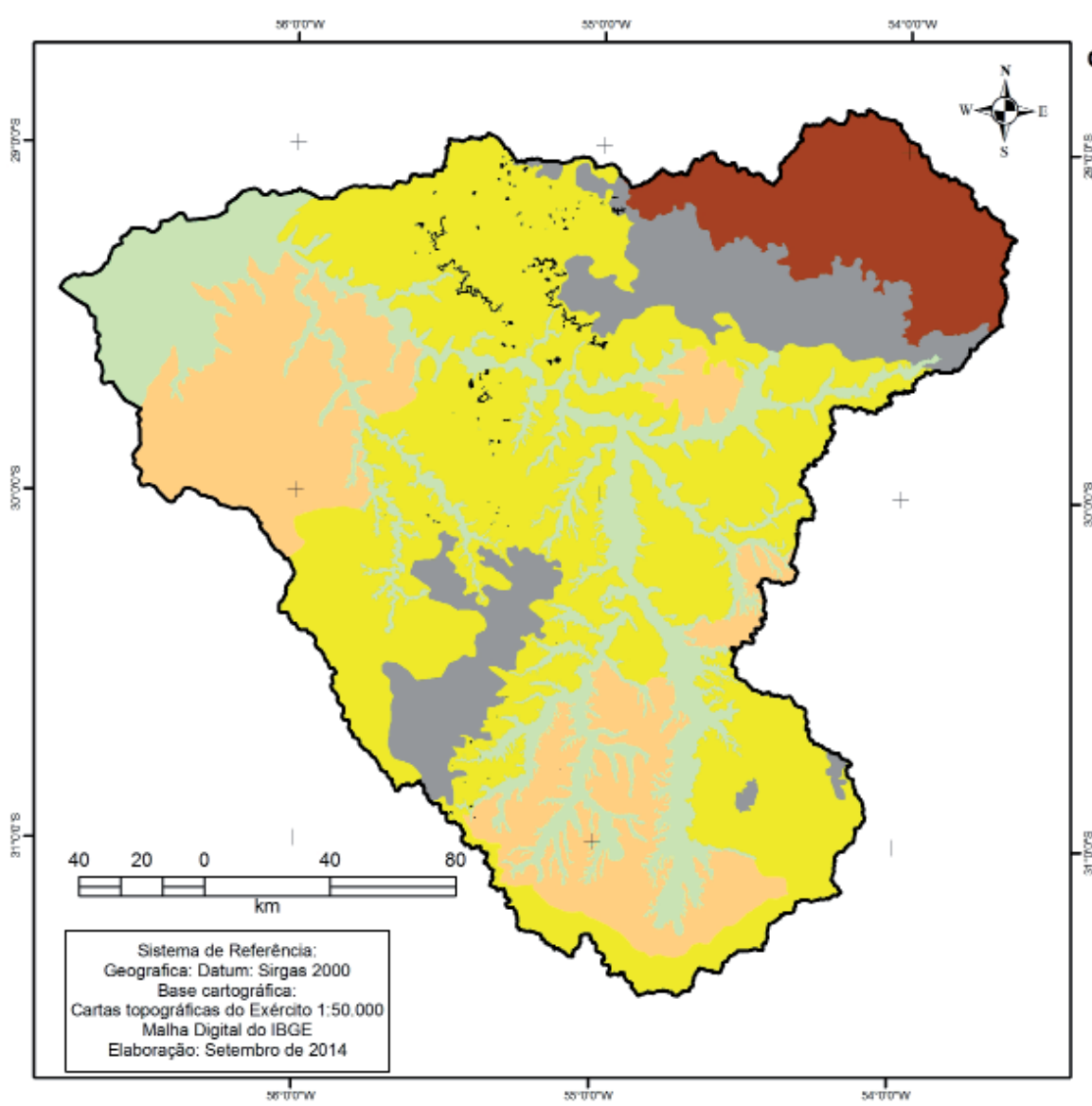

Mapa de Unidades de Relevo da Bacia Hidrográfica do Rio Ibicuí

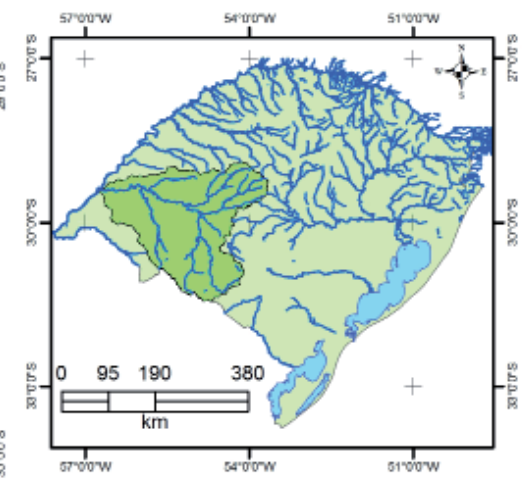

\section{Legenda}

Unidades de Relevo

Colinas

Colinas Suaves

Colinas de Altitude

Associaçăo de Colinas, Morros e Morrotes

Áreas Planas

Morrotes Isolados

+ + escarpa

$\square$ Limite da BHRI

Figura 2 - Mapa de unidades de relevo da BHRI

O substrato litológico que forma a BHRI está representado, principalmente, por rochas do Maciço cristalino e por sequências de rochas sedimentares e vulcânicas da Bacia do Paraná, além de rochas e sedimentos recentes, figura 3.

As rochas do Maciço cristalino, em uma pequena porção, a SE da bacia são representadas por granitos, gnaisses e, com menor representação, xistos e vulcânicas ácidas.

As sequências de rochas sedimentares da Bacia do Paraná, ocorrem no centro-Sul da bacia. As primeiras unidades sedimentares da Bacia do Paraná, aflorantes na BHRI, estão depositadas sobre e na borda do Escudo Sul Rio-grandense.

Em direção a oeste passa para lamitos marinhos, com intercalações carbonáticas, formando uma faixa N-S de exposição, na região SE da bacia.
Estes afloramentos dão lugar, a uma sequência litológica, representada por arenitos e lamitos, distribuída ao longo de faixas laterais caracterizadas por Lavina (1988) como continentais.

O avanço de depósitos continentais é marcado por uma espessa sucessão flúvio-eólica que corresponde à Formação Sanga do Cabral (LAVINA, 1988). Na BHRI esta unidade está muito bem representada e, apesar de ocorrer intercalações, podem ser separadas em duas porções: uma primeira, localizada mais a leste, com predominância de arenitos eólicos; e uma segunda de arenitos com características fluviais que predominam para oeste e norte da bacia, e que se caracterizam pela presença comum de micas.

Já na porção centro-leste da BHRI, em direção ao Rebordo do Planalto, afloram lamitos fossilíferos da Formação Santa Maria (BORTOLUZZI, 1974), 

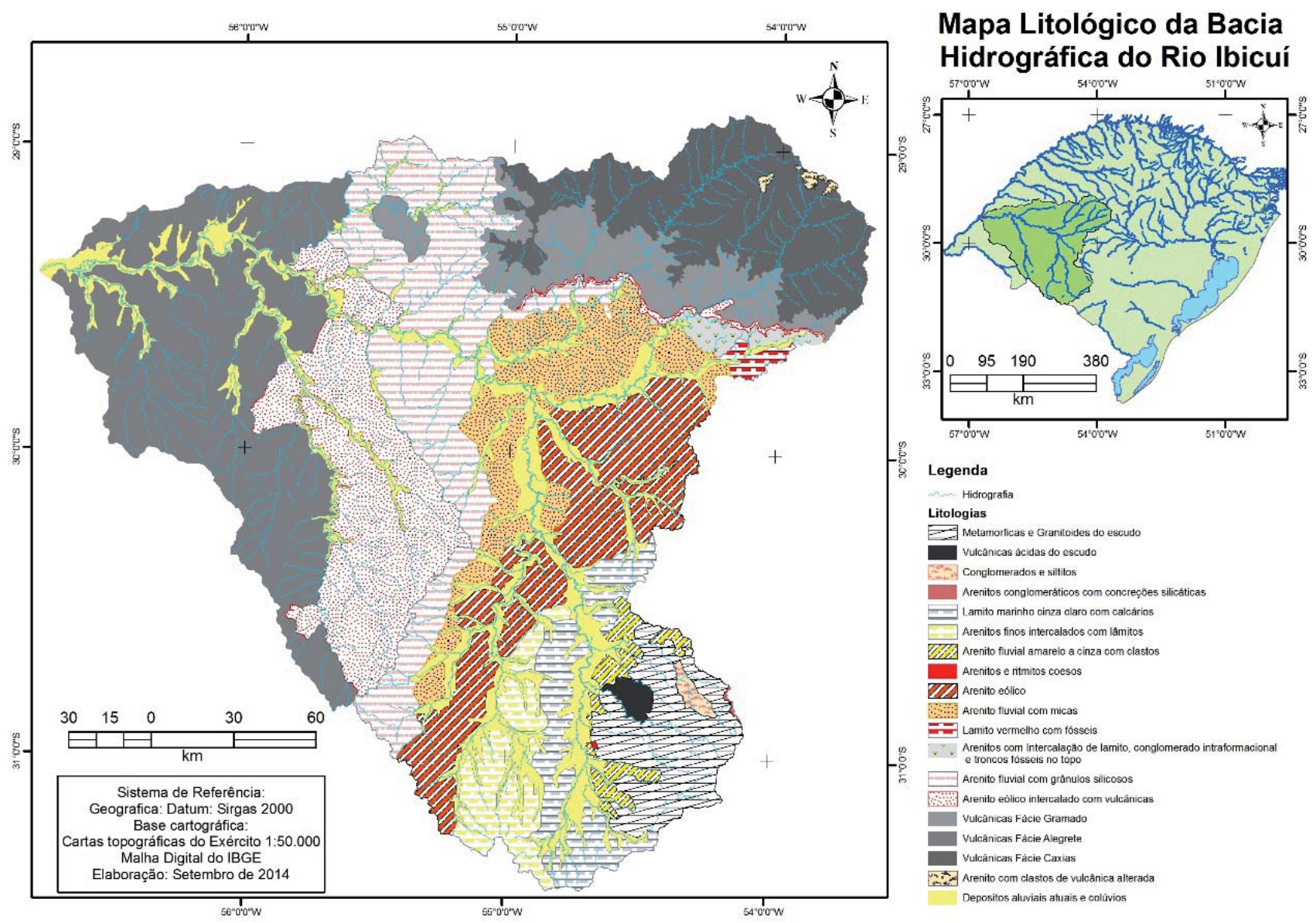

Figura 3 - Mapa litológico da bacia hidrográfica do rio Ibicuí

associados com arenitos finos, conglomerados intraformacionais e, ainda, sobrepostos arenitos com a presença de troncos fósseis.

A partir do rio Jaguari a oeste ocorrem rochas sedimentares de origem ligada a fluxos aquosos, formando uma faixa $\mathrm{N}-\mathrm{S}$, mais espessa a norte do rio Ibicuí, que se estende do município de Jaguari até Santana do Livramento. Essas rochas caracterizam-se por sua textura de areia com grânulos silicosos dispersos, estrutura, por vezes bem definida, de estratos cruzados acanalados e planares.

Arenitos médios a finos de elevada esfericidade e aspecto fosco, róseos, que exibem estratificação cruzada tangencial, de médio a grande porte, afloram em uma faixa delgada junto ao Rebordo e em toda porção centro-oeste da Bacia, associados as rochas vulcânicas.

As rochas vulcânicas são predominantes e ocorrem cobrindo toda a porção norte e oeste da BHRI com variações de estrutura, textura e químicas.

No extremo NE da BHRI ocorrem, em uma pequena área, arenitos de cor avermelhada, às vezes amarelo esverdeados, com granulação variável de fina a média, mal classificados, eventualmente conglomeráticos e constituídos essencialmente de quartzo e vulcânicas alteradas.

Os depósitos recentes estão representados por depósitos fluviais e depósitos coluviais associados à base das encostas mais íngremes.

\section{Unidades Morfolitológicas}

As caraterísticas do relevo e do substrato definem 11 unidades morfolitológicas, que em alguns casos foram divididas em subunidades. O mapa da Figura 4 mostra a distribuição espacial das unidades morfolitológicas e a tabela 1 apresenta a área ocupada pelas unidades e sub-unidade definidas na bacia hidrográfica. 


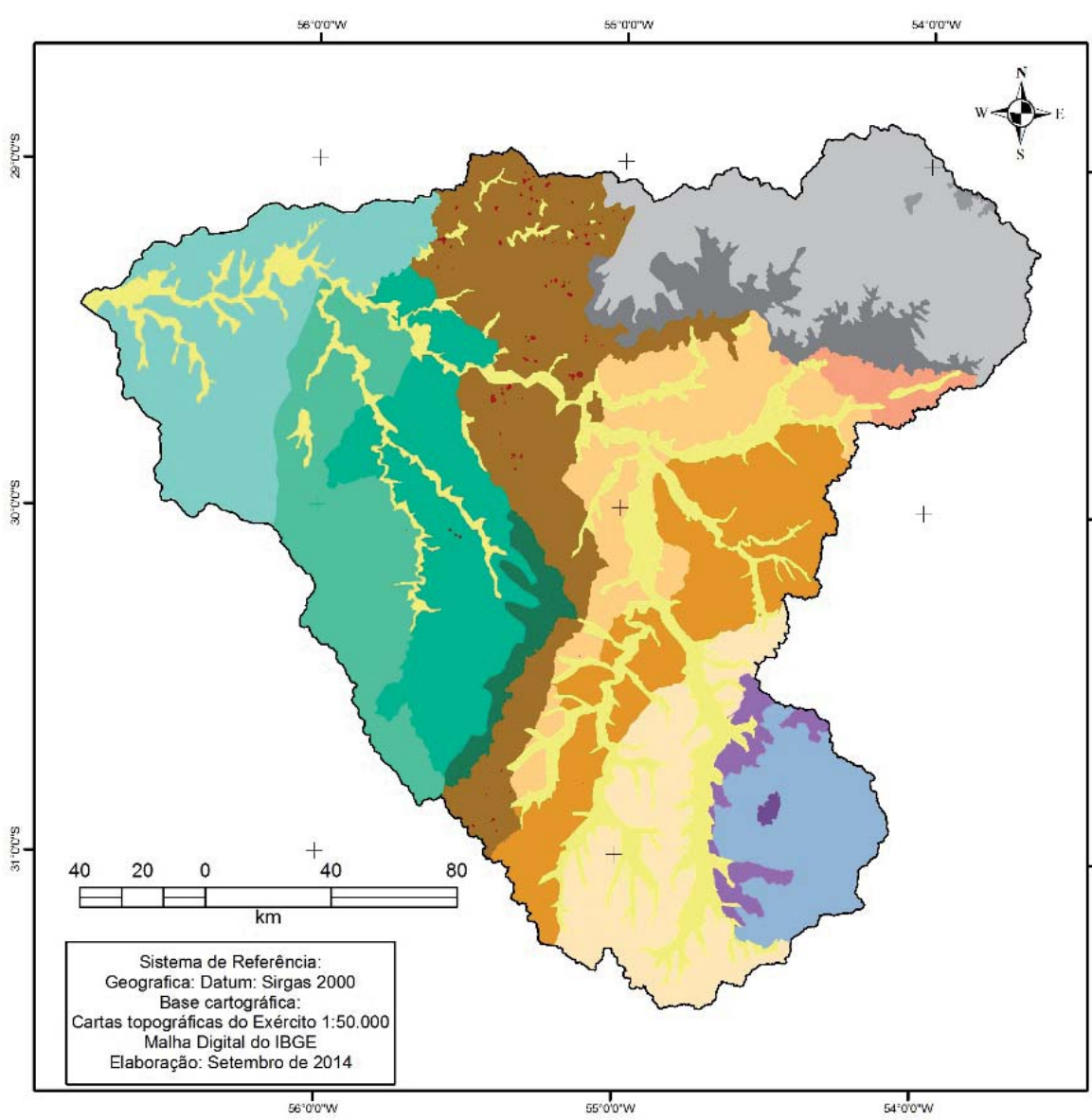

Mapa Morfolitológico da Bacia Hidrográfica do Rio Ibicuí

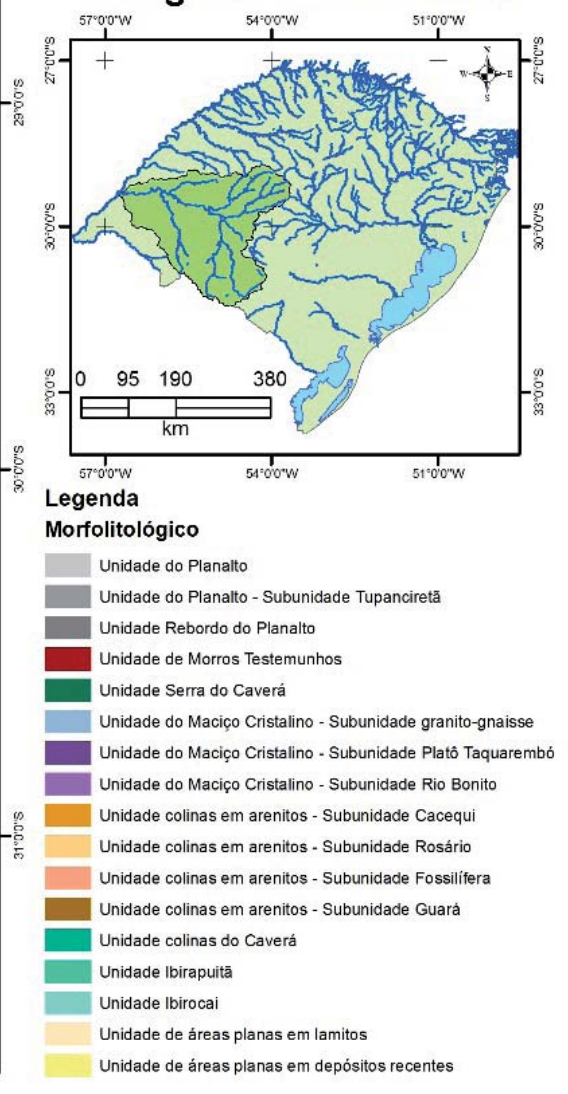

Figura 4 - Mapa morfolitológico da bacia hidrográfica do rio Ibicuí.

Tabela 1: Área das unidades morfolitológicas da bacia hidrográfica do rio Ibicuí

\begin{tabular}{|l|c|c|}
\hline Unidade & Área $\mathbf{~ k m}^{2}$ & Porcentagem \\
\hline Unidade do Planalto & $5.647,97$ & 11,98 \\
\hline Unidade do Planalto - Subunidade Tupanciretã & 74,23 & 0,16 \\
\hline Unidade Rebordo do Planalto & $1.698,13$ & 3,60 \\
\hline Unidade de Morros Testemunhos & 54,38 & 0,12 \\
\hline Unidade Serra do Caverá & 735,02 & 1,56 \\
\hline Unidade do Maciço Cristalino - Subunidade granito-gnaisse & $2.491,53$ & 5,29 \\
\hline Unidade do Maciço Cristalino - Subunidade Platô Taquarembó & 50,29 & 0,11 \\
\hline Unidade do Maciço Cristalino - Subunidade Rio Bonito & 608,10 & 1,29 \\
\hline Unidade colinas em arenitos - Subunidade Cacequi & $4.235,22$ & 8,98 \\
\hline Unidade colinas em arenitos - Subunidade Rosário & $3.021,12$ & 6,41 \\
\hline Unidade colinas em arenitos - Subunidade Fossilífera & 544,25 & 1,15 \\
\hline Unidade colinas em arenitos - Subunidade Guará & $6.065,24$ & 12,87 \\
\hline Unidade colinas do Caverá & $4.256,14$ & 9,03 \\
\hline Unidade Ibirapuitã & $3.966,97$ & 8,41 \\
\hline Unidade Ibirocai & $4.773,79$ & 10,13 \\
\hline Unidade de áreas planas em lamitos & $3.110,75$ & 6,60 \\
\hline Unidade de áreas planas em depósitos recentes & $5.808,74$ & 12,32 \\
\hline
\end{tabular}




\section{Unidade do Planalto}

Esta unidade corresponde a 11,98\% da área da bacia e ocorre nas maiores altitudes da bacia, acima de $300 \mathrm{~m}$, constituindo um relevo ondulado com encostas com declividades entre 5-15\% e amplitudes de 40-60m (Figura 5A), com pequeno predomínio de porções de encosta com perfil côncavo variando de convergentes a divergentes. Nas vertentes de perfil convexo os padrões divergentes são mais representativos.

Nessas áreas as nascentes desenvolvem, em porções côncavo-convergente pequenas bacias semi-circulares com solos hidromórficos que representam porções de maior alteração do substrato devido, provavelmente, a intersecções de linhas de fraturas nas rochas vulcânicas.

Os processos de alteração criam mecanismos internos de subtração de constituintes (erosão geoquímica), modificando as organizações estruturais no interior dos perfis e, por consequência, o modelado superficial.

As depressões inicialmente isoladas dão início a uma modificação do relevo por posterior incorporação delas à rede de drenagem.

O uso é agropastoril devido a boa condição do relevo para práticas agrícolas e, muitas vezes essa depressões com surgência d'água são barradas servindo para desedentação do gado.

No extremo NE, dessa área a ocorrência de arenitos confere um aspecto marcante que são as incisões erosivas que, por vezes, geram voçorocas. Esta característica permite definir uma subunidade denominada subunidade Tupanciretã, representando somente $0,16 \%$ da bacia.

\section{Unidade Rebordo do Planalto}

Esta unidade representa uma área onde ocorre a passagem das porções com altitudes elevadas do Planalto para as áreas de altitudes baixas da Depressão (Figura 5B). Ocupa 3,6\% da área da bacia e é representado por formas, predominantes, de Morros e Morrotes, que se caracterizam por declividade de encosta superior a $15 \%$ e amplitude variando de $60 \mathrm{~m}$ a $140 \mathrm{~m}$. As encostas nesta unidade são, predominantemente, com perfil côncavo variando do padrão côncavo-convergente e côncavo-divergente.
Nas vertentes de perfil convexo predomina o padrão convexo-divergente. Em geral observa-se que ocorre uma variação do perfil côncavo no topo a convexo na base.

O substrato é formado por rochas vulcânicas com intercalações de arenitos e a formação de depósitos de colúvio na base das encostas formando o perfil com variação do topo para a base.

Os processos morfogenéticos são significativos e se caracterizam por rastejos, que marcam a encosta com ondulação, movimentos de rocha e solos seguindo porções convergentes da encosta.

O relevo determina o uso que é caracterizado por pequenas lavouras de subsistência e, comumente, plantação de fumo, devido ao apoio das indústrias de tabaco, importantes no Rio Grande do Sul.

\section{Unidade Serra do Caverá}

$\mathrm{Na}$ área centro-sul da BHRI ocorre uma associação de colinas, morrotes e morros alinhados na direção NE, conhecida, regionalmente, como Serra do Caverá (Figura 5C), que ocupa 1,56\% da área da bacia. Constitui os divisores de águas de dois, dos mais importantes, rios da bacia: o rio Ibirapuitã e o rio Santa Maria.

O substrato aflorante, predominante, são rochas vulcânicas com intercalações de arenitos, conferindo ao topo, formas arredondadas quando vulcânicas e tabular quando o arenito é o responsável por manter o relevo. Em porções muito dissecadas as vulcânicas ocorrem somente como delgadas capas no topo do morrote.

A ocorrência de arenitos entre derrames, muitas vezes, gera surgências que permitem a instalação de vegetação arbórea-arbustiva formando um anel ao redor dos morros e morrotes.

O uso é restrito a pecuária devido a inclinação das encostas e pela presença de muitos blocos dispersos nos solos. Ocorrem processos de movimentos de massa e pequenas corridas em porções convergentes da encosta.

\section{Unidade de Morros Testemunhos}

Esta unidade se caracteriza pela ocorrência de formas de relevo identificadas por encostas com decli- 
vidades superiores a $15 \%$, amplitudes entre 20 e $60 \mathrm{~m}$, nos morrotes, e 120 a 140m, nas formas de morros.

Os morros e morrotes isolados (Figura 5D) ocupam $0,12 \%$ da área da bacia e marcam o recuo da escarpa do Planalto, representando a evolução dos processos intempéricos e erosivos. Apresentam formas com topos ondulados a tabular, depósitos de colúvio na base e desenvolvimento de vegetação arbórea.

Em geral os topos estão mantidos por camadas de rochas vulcânicas. Entretanto são comuns topos planos onde as elevações são mantidas por camadas de arenito cimentados chamados, regionalmente, de Cerros.

Os morros e morrotes formados em rochas vulcânicas apresentam uma vegetação arbórea bastante representativa junto as encostas íngremes. Nos cerros ocorre um anel periférico, disperso entre blocos de rocha, de vegetação arbórea-arbustiva com espécies apresentando visíveis caracteres xeromórficos (ALVES \& ROBAINA, 2010).

\section{Unidade do Maciço Cristalino}

Essa unidade é representada por formas de colinas caracterizadas com inclinações inferiores a $15 \%$ (Figura 5E), amplitudes ao redor de $60 \mathrm{~m}$, interflúvios curtos e drenagens encaixadas em fraturas. $\mathrm{O}$ substrato aflorante na BHRI é, predominantemente, formado por gnaisses e granitos, ocorrendo subordinado vulcânicas e metasedimentares. Essa variação litológica produz variação de formas que permite definir subunidades.

A subunidade granito-gnaisse é caracterizada por uma associação de solos rasos e profundos, dependendo da ação dos processos de intemperismo em porções mais ou menos fraturadas. A ocorrência de colinas com presença de afloramentos de matacões marca como principal característica desta unidade que ocupa 5,29\% da área da bacia.

Associado as colinas ocorre um platô com relevo suavemente ondulado a plano, altitudes acima de $300 \mathrm{~m}$ e com as borda marcadas por encosta com inclinações superiores a 15\%, substrato de rochas vulcânicas e os solos rasos. Essas características definem a subunidade denominada Platô Taquarembó que ocupa $0,11 \%$ da BHRI.
$\mathrm{Na}$ borda das rochas cristalinas do Escudo ocorrem rochas areníticas de textura média a grossa de média a baixa coesão, que formam um relevo na forma de colinas que são mais suscetíveis a processos erosivos, classificada como subunidade Rio Bonito que ocupa $1,29 \%$ da área da bacia.

\section{Unidade colinas em arenitos}

As colinas em substrato de arenitos são formas definidas por amplitudes entre $40-60 \mathrm{~m}$ e declividade inferior a 15\% (Figura 6 A, B e C).

$\mathrm{O}$ substrato de arenitos apresenta diferenças composicionais e textural que refletem em comportamento frente aos processos superficiais e de uso. As variações nos teores de ligantes nos arenitos podem gerar respostas aos processos superficiais de intemperismo e erosões bastante diferentes que respondem na superfície com feições como voçorocas e areais.

Estas características determinaram a divisão da unidade em quatro subunidades: subunidade Cacequi, subunidade Guará, subunidade Rosário e subunidade Fossilífera.

A subunidade Cacequi, ocupa 8,98\% da área da bacia, é constituída por um substrato de arenitos friáveis, homogêneos, com solos espessos e arenosos apresenta suscetibilidade alta a erosão. Nestas áreas se observa processos erosivos lineares acelerados, que geram voçorocas, compreende a porção central da bacia, junto a bacia do rio Cacequi.

O uso é agrícola e pecuária, mas observa-se nos últimos anos um aumento da atividade de silvicultura, em áreas adquiridas pelas empresas, devido ao valor mais baixo das terras, associado a suscetibilidade erosiva.

A subunidade Guará, apresenta um substrato de arenitos friáveis, com grânulos silicosos dispersos e uma associação com áreas com significativos processos de arenização (Suertegaray et al 2012). Marcam uma condição de ampla exposição de materiais arenosos, friáveis que são reflexo da erosão aquosa e eólica. Formam uma porção limitada pelos rios Itu e Jaguari na margem direita e Lajeado Grande e Itapevi, na margem esquerda do Ibicuí, compondo $12,87 \%$ da área da bacia.

Por vezes, ocorrem colinas com vegetação tipo butiá-anão (Butia lallemantii, Deble e Marchiori 

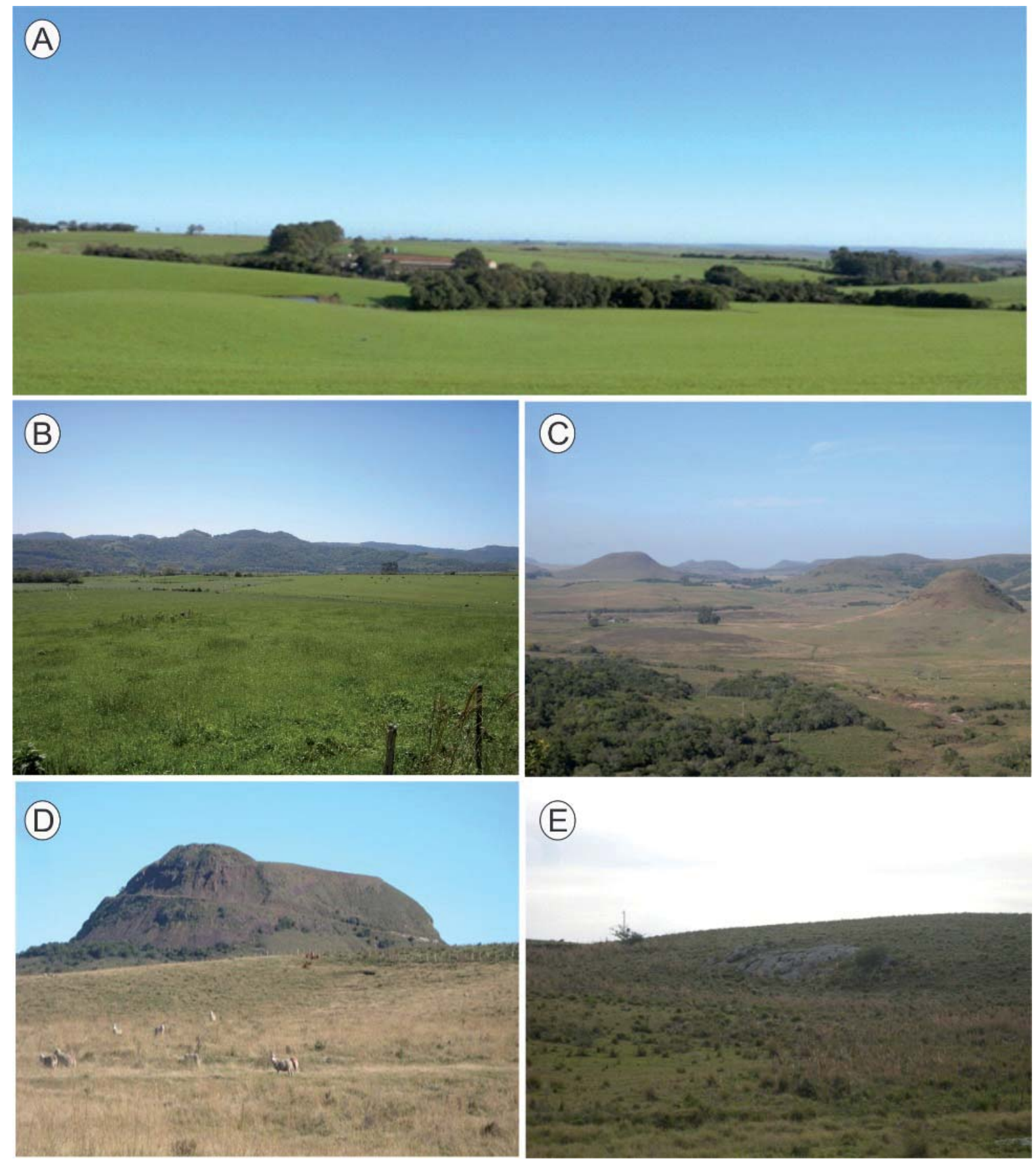

Figura 5 - "A” colinas sobre substrato de rochas vulcânicas da Fm. Serra Geral - Unidade do Planalto - Município de Júlio de Castilhos; " $B$ ” rebordo do planalto, porção com encostas escarpadas, marca o limite entre o Planalto da Serra Geral e a Depressão Periférica do Rio Grande do Sul - Unidade Rebordo do Planalto- Município de São Pedro-2012 ; “C” Associação de colinas morros e morrotes compondo a Unidade Serra do Caverá - Município de Rosário do Sul - 2014; “D” morro testemunho, essas feições marcam a evolução dos processos erosivos sobre porções elevadas topograficamente - Município de Santana do Livramento - 2013; “E” colina com afloramento de rocha metamórfica, devido a elevada resistência da rocha no topo das colinas é comum o afloramento rochas - Município de Dom Pedrito - 2013.

- Arecaceae), que constitui verdadeiros palmares de extensões reduzidas, conferindo um aspecto de savana à vegetação campestre.

Nesta unidade predomina o uso agropastoril, mas houve um incremento significativo do uso para silvicultura na última década, por se constituírem em terras com baixo valor para a produção agrícola.

A subunidade Rosário, ocupa 6,41\% da área da 
bacia, é constituída por arenitos que variam de textura médio a fina, com presença de argila na matriz. O uso é predominantemente agrícola e ocorrem processos erosivos que formam ravinas de pouca profundidade.

Os solos são, predominantemente, rasos e comumente apresentam hidromorfismo e o uso é dominantemente agropastoril.

A subunidade Fossilífera ocorre em uma área a leste da BHRI, compõem 1,15\% da bacia, com ocorrência fossilífera muito significativa, formado por fósseis de vertebrados e troncos.

Devido à importância fossilífera foram criados alguns sítios paleontológicos, mas predomina o uso agropastoril na unidade.
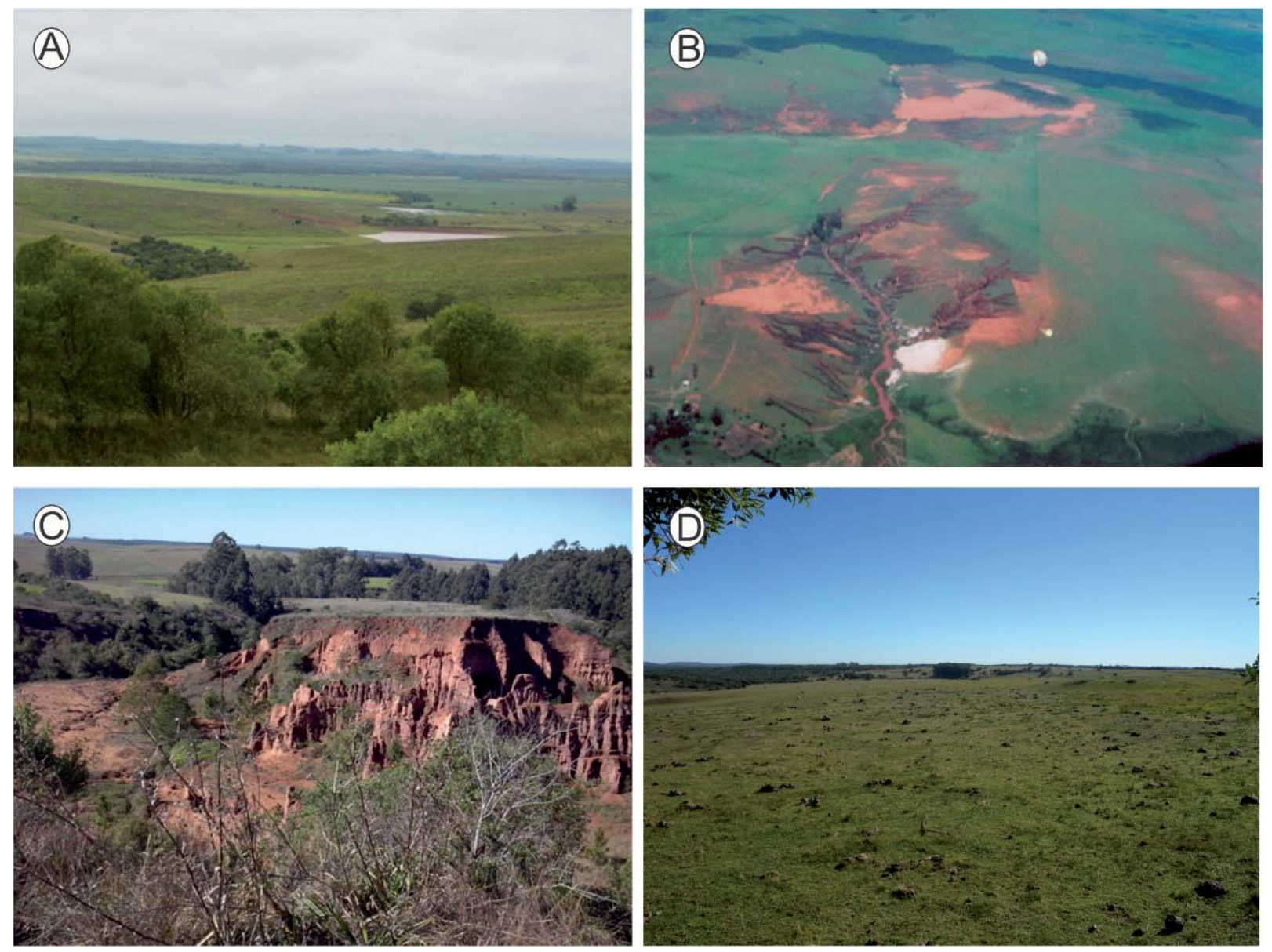

Figura 6 - "A” colinas sobre arenitos ao fundo é possível observar uma suavização nas colinas, marcando o contato entre substrato arenítico para lamitos - município de Rosário do Sul - 2014; “B” processos erosivos (Voçorocas e areais) sobre colinas areníticas - município de São Borja - 2009 ; “C” interior de uma voçoroca, o processo incisivo escavou o solo e a rocha até atingir o nível Freático - município de Cacequi; " $D$ ” colinas com inclinação entre 5\% sobre substrato vulcânico - município de Alegrete - 2014. 
Processos de ravinamento podem ocorrer em contato dos substratos associado a surgências.

\section{Unidade Ibirapuitã}

Esta unidade, com uma área de 8,41\% da bacia, é formada de colinas com amplitudes entre 40-60m, declividades entre 5\% e 15\% com substrato de rochas vulcânicas (Figura 7A).

As rochas vulcânicas que apresentam respostas diferentes aos processos superficiais em função da porção do derrame exposta a ação dos agentes superficiais. Na parte superior dos derrames é encontrada uma porção rica em vesículas e amígdalas que são facilmente afetados pelos processos de alteração, gerando solos bem desenvolvidos. A porção de base dos apresenta juntas horizontais, o que deve ser resultado, pelo menos em parte, do escoamento laminar da lava no seu interior. Já a porção central do derrame apresenta um conjunto de juntas verticais e textura cristalina, apresentando maior resistência aos processos de alteração, condicionando solos menos desenvolvidos. Em derrames com significativo desenvolvimento de diaclases horizontais pode gerar baixa permeabilidade e restrita ação dos agentes de intemperismo em profundidade.

Os solos rasos e a comum ocorrência de afloramentos de rochas dificultam atividade agrícola, sendo a pecuária a atividade predominante na unidade.

\section{Unidade Ibirocai}

Esta unidade está representada, dominantemente, por colinas suaves (Figura 7B) sobre um substrato de rochas vulcânicas, que podem ser intercaladas com arenitos. Formam a porção oeste da BHRI em direção a foz junto ao rio Uruguai, compreendendo 10,13\% da bacia.

A característica são as altitudes inferiores a $100 \mathrm{~m}$, formas com amplos interflúvios, formadas por encostas com amplitudes entre 20 e 40m e declividades entre $2 \%$ e $5 \%$. A baixa inclinação do relevo confere possibilidade de hidromorfismo. O substrato de rochas vulcânicas determina comportamentos diferentes frente aos processos superficias, podendo gerar solos rasos até bem desenvolvidos, mas em geral com argilas 2:1 pela baixa capacidade de transporte lateral dos prudutos das reações.

O uso agrícola é predominante, com lavouras de arroz e soja e subordinado a pecuária.

\section{Unidade de áreas planas em lamitos}

Esta unidade está associada a substrato de arenitos, mas especialmente, de lamitos marinhos de cor bege a cinza, ocupando 6,6\% da área da bacia.

A baixa permeabilidade da rocha e o relevo formado por amplos interfluvios e área planas com declividades ao redor de 2\% (Figura 7C) confere sitações de hidromorfismo e elevado conteúdo de argilas 2:1.

Os materias superficias, pegajosos e de baixo atrito, determinam grandes dificuldades, até mesmo, impedindo a circulção nas estradas não pavimentadas que cruzam a área.

O uso é restrito pelas condições dos solos à cultura de arroz, mas nos períodos entre safra e mais secos utiliza-se a pecuária.

\section{Unidade de áreas planas em depósitos recentes}

Os depósitos recentes formam os depósitos de canal e de transbordamento dos rios que compõem a BHRI (Figura 7D) e ocupam 12,32\%.

Nos rios da margem direita, na porção de alto e médio curso, os depósitos são constituídos, principalmente, de cascalho e blocos de rochas vulcânicas. Os sedimentos no baixo curso são constituídos, principalmente, de areias que estão sendo retrabalhadas, moderadamente classificadas.

Os rios da margem esquerda escoam sobre substrato de rochas vulcânicas e formam, pouco expressivos, depósitos de canal, exceto o Rio Santa Maria que forma importante depósitos de barra de meandro e barra de pontal no baixo curso, que têm importante papel econômico pela extração de areia.

O rio Ibicuí, propriamente dito, forma significativos depósitos de canal, que também é explorado para a extração de areia.

Na planície de inundação ocorrem os depósitos mais finos constituídos de areia, silte e argila em áreas planas apresentam condições de hidromorfismo e são utilizadas para cultura de arroz. 

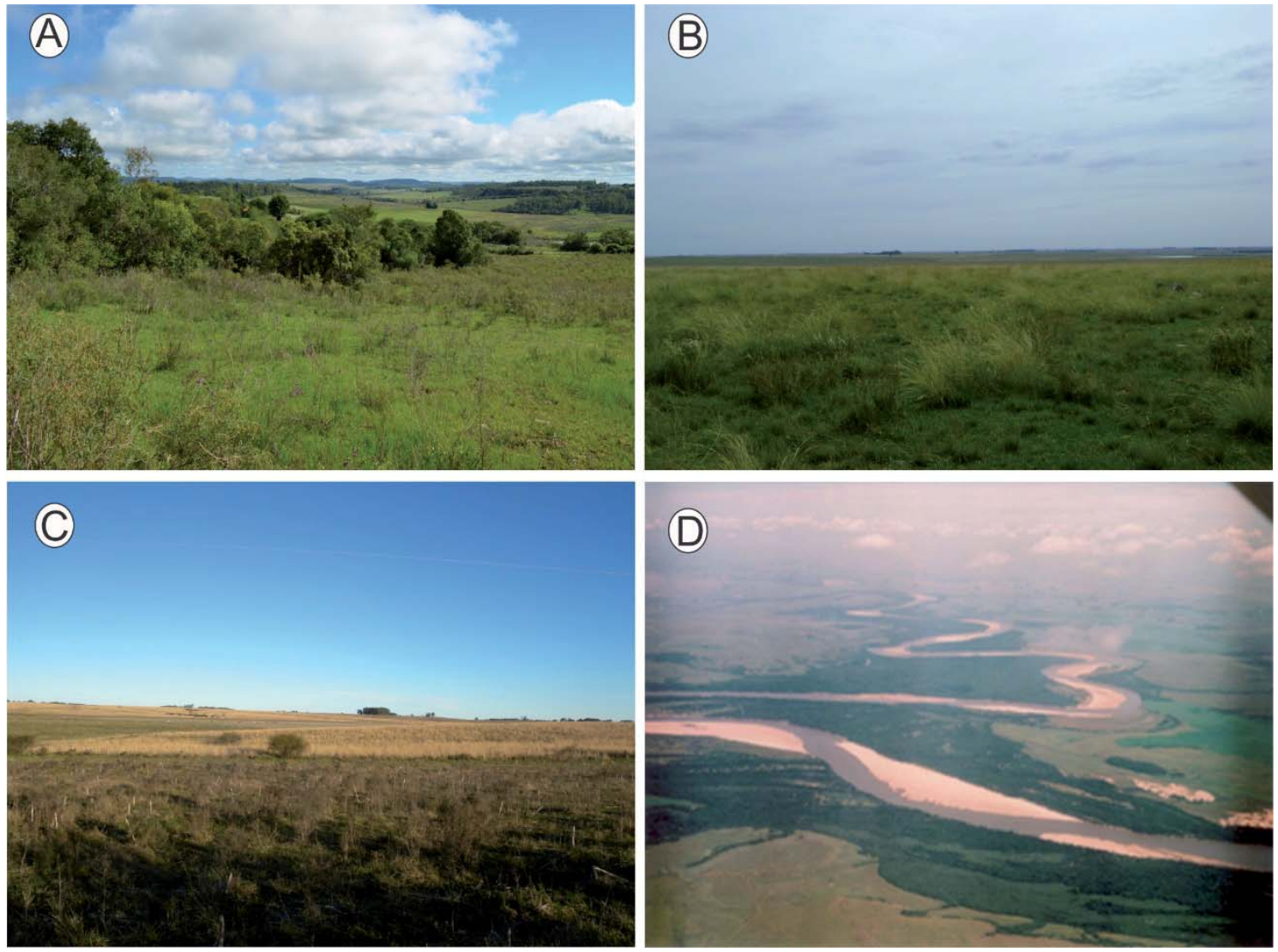

Figura 7 - “A” colinas da Unidade Ibirapiutã - município de Santana do Livramento - 2014; “B” colinas suaves sobre rochas vulcânicas é comum nessas áreas solos rasos, por vezes é comum o afloramento de rochas tanto vulcânicas quanto arenitos intertrap - município de Alegrete - 2014; “C” relevo comum a áreas com substrato composto por lamitos de origem marinha - município de Dom Pedrito - 2014; “ $D$ ” depósitos de barra de pontal nas margens do rio Ibicuí entre o limite dos municípios de Manoel Viana e Alegrete - 2008

\section{Considerações Finais}

O presente trabalho desenvolveu uma análise dos elementos do meio físico, caracterizados pelo relevo e litologias presentes. Esta análise permitiu definir unidades homogêneas denominadas morfolitológicas.

As unidades foram relacionadas com os processos superficiais atuantes e que deixam registro na superfície do terreno na forma de ravinas, voçorocas e areais, mostrando a significativa relação com características do substrato e do relevo.

O relevo e o substrato litológico mostram-se diretamente relacionado com os processos de formação do solo e, portanto, uma cartografia morfolitológica possui grande potencial para ser utilizado em trabalhos de levantamento de solos considerando que as formas do relevo exercem papel decisivo no tempo de exposição dos materiais, na intensidade e direção do fluxo da água e as litologias na resistência dos materiais a processos físico-químicos da superfície.

O uso e a ocupação da bacia está refletida nas características das unidades morfolitológicas, dificultando ou favorecendo determinada atividade. A atividade de rizicultura acontece onde a água é disponível; os campos pedregosos do oeste têm a atividade pecuária mais importante que a agrícola; e as áreas de silvicultura estão em colinas arenosas, devido a capacidade do eucalipto em se desenvolver nestas condições, mas, também, porque as atividades agrícolas são dificultadas e as terras apresentam menor custo para aquisição.

Além disso, um aspecto importante a considerar nas colinas arenosas, especialmente da unidade Guará, é a ocorrência de espécies como o butiá-anão (Butia lallemantii) que recentemente foi considerado espécie endêmica dos campos gaúchos, bem como as próprias formações campestres pouco conhecidas. 


\section{Agradecimentos}

Os autores agradecem o apoio do CNPQ e do programa franco-brasileiro CAPES-COFECUB, Projeto n580/07.

\section{Referências Bibliográficas}

ALVES, F. S.; ROBAINA L. E. S. Estudo Morfolitológico da Bacia Hidrográfica do Arroio Lajeado Grande - Oeste do RS. Ciência e Natura, UFSM, 32 (2): 141-162, 2010.

BARREIROS, A. M. Estudo sobre a pedogênese na transição arenitos - basaltos na bacia do córrego Gurupá (Floraí,PR). Dissertação de Mestrado - Departamento de Geografia - USP - 2013. 131p.

BORTOLUZZI, C.A. Contribuição à geologia da Formação Santa Maria, Rio Grande do Sul, Brasil. Pesquisas, Porto Alegre, 4(I):7-86, 1974.

CHRISTOFOLETTI, A. Geomorfologia. São Paulo: 2 ed. Edgard Blücher, 1980. 188 p.

ENRÍQUEZ J.E.I. Dinámica de flujos de lodos. Revista Unimar, 2012.. Número 60, jul-dic 2012, 43-54

GUADAGNIN, P. M. A.; TRENTIN, R.. Compartimentação Geomorfométrica da Bacia Hidrográfica do Arroio Caverá - RS. Geo UERJ, v. 25, p. 183-199, 2014.

INSTITUTO DE PESQUISAS TECNOLÓGICAS. IPT. Mapeamento Geomorfológico do Estado de São Paulo. São Paulo. Escala 1:500.000, v. 2, 1981. 130 p.

LAVINA, E. L. The Passa Dois Group. In: INTERNATIONAL GONDWANA SYMPOSIUM, 7, 1988. São Paulo. Field excursion guide book. São Paulo: Instituto de Geociências, 1988. p. 24-30. 1988.

MENEZES, D. J. ; SCOTTI, A. A. V.; ROBAINA, L. E. S. ; TRENTIN, R. . Zoneamento geoambiental do município de São Pedro do Sul RS. Geografias Online (UFMG), v. 13, p. 68-80, 2012.

MENEZES, D. J. ; TRENTIN, R.; ROBAINA, L. E. S. ; SCCOTI, A. A. V.. Compartimentação geomorfológica do município de São Pedro do Sul/RS. Boletim Gaúcho de Geografia, v. 40, p. 268-279, 2013.

PALLÍ I BUXÓ, L.. Contribución al estudio morfolitológico del sector costero central del macizo de Begur (Girona). Estudi General, 1981: Núm.: 1 (vol. 2) 231-240.
PAULA, P. M. Mapeamento de Unidades Litomorfológicas em Bacias Hidrográficas com processos de Arenização, Alegrete-RS. 2006. 69 f. Dissertações (Mestrado em Geografia) - Universidade Federal do RioGrande do Sul, Porto Alegre, 2006. ROBAINA, L. E. S.; SCCOTI, A. A. V.; TRENTIN, R.. Zoneamento Morfolitológico no Município de Manoel Viana-RS. Geografia (Londrina), v. 22, p. 27-37, 2013.

ROBAINA, L.E.S.; TRENTIN, R.; BAZZAN, T.; RECKZIEGEL, E.W.; VERDUM, R.; DE NARDIN, D. Compartimentação geomorfológica da bacia hidrográfica do Ibicuí, Rio Grande do Sul, Brasil: proposta de classificação. Revista Brasileira de Geomorfologia, v.11, n.2, p.11-23, 2010

SCCOTI, A. A. V.; ROBAINA, L. E. S.; TRENTIN, R. Compartimentação do relevo no município de Manoel Viana-RS. Ciência e Natura, v. 35, p. 64-70, 2013.

SOUTO, R. Deserto: uma ameaça? Secretaria da Agricultura do RS, DRNR, Diretoria Geral, porto Alegre, 1985.

SUERTEGARAY, D. M. A. O Rio Grande do Sul Descobre os Seus "Desertos". Ciência e Ambiente, Santa Maria, n.11, p. 33-52, 1995.

SUERTEGARAY, D. M. A., et al. Atlas de Arenização: Sudoeste do Rio Grande do Sul. Porto Alegre: Secretaria da Coordenação e Planejamento, 2001. v. 1. Atlas.

SUERTEGARAY, D. M. A.; SILVA, L. A. P.; GUASSELI, L. A. Arenização: Natureza Socializada. Porto Alegre: Compasso. 2012.

TRENTIN, R.; ROBAINA, L. E. S. Mapeamento Morfolitológico da Bacia Hidrográfica do Rio Itú. In: VI Simpósio Nacional de Geomorfologia/regional Conference on Geomorphology, 2006, Goiânia. Anais, 2006. p. 1-15.

TRENTIN, R.; ROBAINA, L. E. S.. Unidades geoambientais na bacia hidrográfica do rio Itu - oeste do estado do rio grande do sul, brasil. Revista do Departamento de Geografia (USP), p. 267-287, 2012.

TRENTIN, R.; ROBAINA, L. E. S.; SCCOTI, A. A. V.. Mapeamento geomorfológico do município de Manoel VianaOeste do Rio Grande do Sul- Brasil. Geociências (São Paulo. Online), v. 32, p. 333-345, 2013.

TRENTIN, R.; SANTOS, L. J. C.; ROBAINA, L. E. S.. Compartimentação Geomorfológica da Bacia Hidrográfica do Rio Itu Oeste do Rio Grande do Sul - Brasil. Sociedade \& natureza (UFU. Online), v. 24, p. 127-142, 2012. 
Zoneamento Morfolitológico da Bacia Hidrográfica do Rio Ibicuí e sua Relação com Processos Superficiais

VERDUM, R. Approche Géographique des “Deserts” Dans les Communes de São Francisco de Assis et Manuel Viana Etat du Rio Grande do Sul, Brésil. Tese de Doutorado. França: Université de Toulouse Le Mirail - UFR de Géographie, 1997. 211p.
WILDNER, W; RAMGRAG, G. E.; LOPES R. C.; IGLESIAS, C. M. F. Mapa Geológico do Estado do Rio Grande do Sul. Escala 1:750000. CPRM, Serviço Geológico do Brasil. Porto Alegre, RS. 2006. 